\title{
Note on Terminology and Names
}

Anthropological prose typically suggests that societies and cultures are holistic, bounded milieux (e.g., "Brazil," "Japanese culture"). It likewise suggests that people are overwhelmingly cultural or social products ("Japanese-Brazilians"). Such notions are incorrect, but language is approximate and evocative, not precise and constitutive. In writing this book I often found ethnic and national terminology a practical shorthand-one cannot endlessly explain, repeated disclaimers are tedious, and neologisms have a high cost. Characterizing people as "Brazilians" simply points to one (and perhaps not a very important) aspect of their identities, just as describing a cultural practice as "Brazilian" simply means that it is widely employed by "Brazilians." I urge the reader to resist the inference that people live within bounded cultures, or that cultures produce them, or that they are exemplars of social categories. My reservations about such claims will, I trust, become obvious.

Ultimately, this is not a study of "Japanese-Brazilians," "Brazilian culture," or "Japanese culture." It is about men and women, girls and boys, who engage the categories to which they are assigned and the circumstances that befall them. In other words, their lives, which are not cultural artifacts and are not reducible to a set of social coordinates, are the chief topic of this book.

With respect to names, I use people's real names only when I am confident that my portrayal is in no way hurtful or prejudicial. To those I formally interviewed I promised anonymity, though not everyone cared about that. Personal names appearing in the acknowledgments and photo captions are real names. All others are pseudonyms unless otherwise noted. I have likewise assigned fictitious names to almost all companies. 


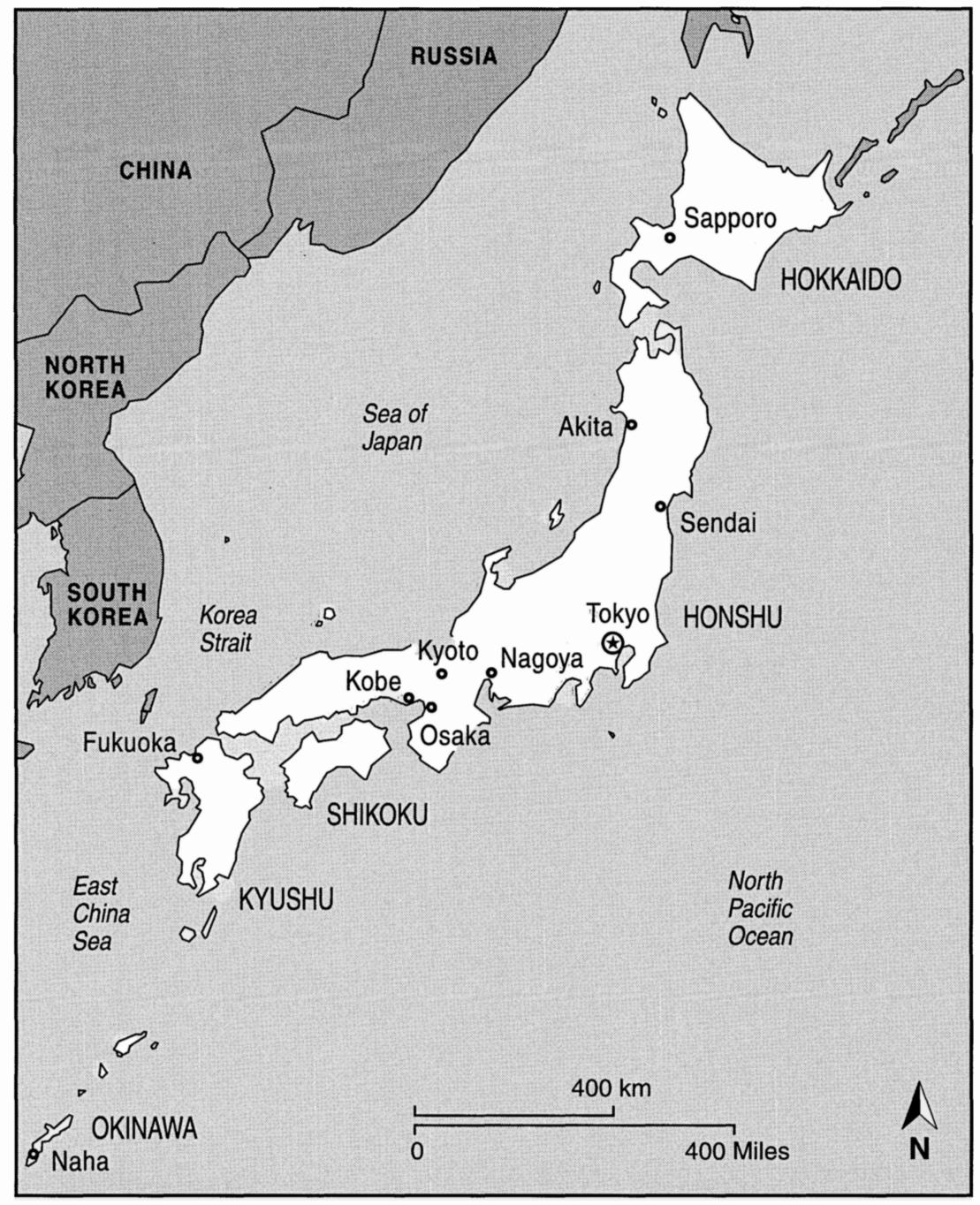

Map I. Japan 
Names of Japanese are customarily written surname first. But Brazilians with Japanese names write them surname last. Adhering to national conventions, usually a desirable way to treat name order, would in this case unfortunately mandate differing treatment of Japanese and Japanese-Brazilian names, causing confusion to readers unfamiliar with Japanese names. With some misgivings, for the sake of consistency I write all names in this book in the Brazilian style, given name followed by surname. 


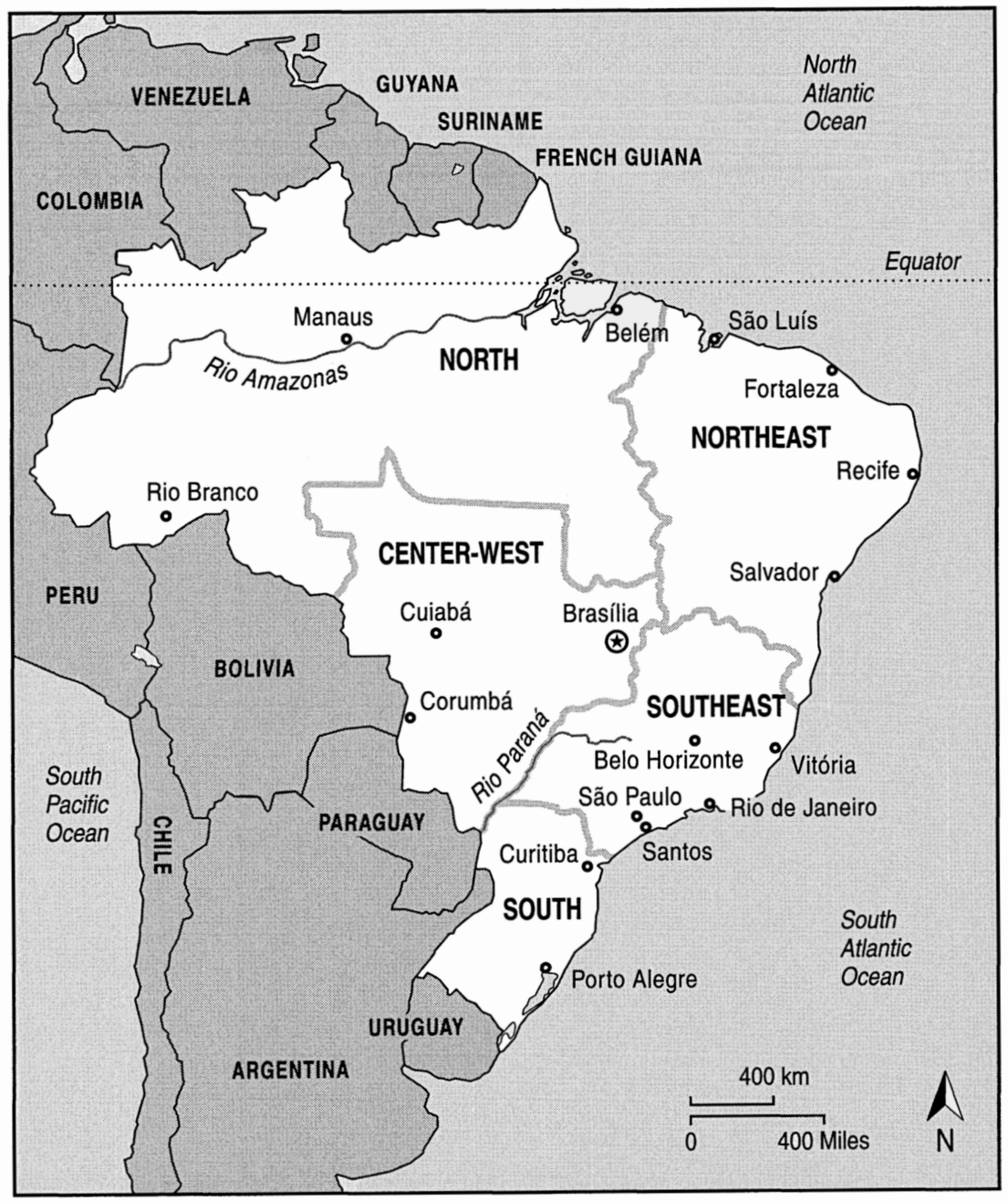

Map 2. Brazil 
